\title{
PERÍODOS DE SECAGEM NA QUALIDADE FISIOLÓGICA DE SEMENTES DE Licania rigida Benth
}

\section{DRYING PERIODS ON THE PHYSIOLOGICAL QUALITY OF Licania rigida Benth SEEDS}

\author{
Eliane Duarte Brandão ${ }^{1}$ Manoel Alexandre Diniz Neto ${ }^{2}$ Luciana Rodrigues de Araújo ${ }^{3}$ Ivandro de \\ França da Silva ${ }^{4}$ Wagner Magno Catão Barbosa ${ }^{5}$ Maria Gabriela Souza Maioli ${ }^{6}$
}

\section{RESUMO}

A oiticica (Licania rigida Benth) é uma espécie arbórea perene, oleaginosa, que tem grande importância na região semiárida do nordeste do Brasil por preservar as margens dos rios e riachos temporários. Devido à escassez de informações referentes à dessecação de suas sementes, o trabalho teve como objetivo avaliar a qualidade fisiológica de sementes de oiticica submetidas a diferentes períodos de secagem. O delineamento experimental foi inteiramente ao acaso e os dados, submetidos à análise de variância e de regressão polinomial. Os tratamentos foram avaliados pela determinação do teor de água, emergência de plântulas, testes de vigor (primeira contagem, índice de velocidade de emergência, massa fresca e seca da parte aérea e raízes), e análise de crescimento (número de folhas, altura de plântulas e diâmetro caulinar). As sementes de oiticica comportam-se como ortodoxas, com elevada emergência à medida que seu teor de água é reduzido; o nível crítico de água, abaixo do qual há perda de viabilidade, está em torno de $6 \%$.

Palavras-chave: oiticica; emergência; dessecação; vigor.

\begin{abstract}
The oiticica (Licania rigida Benth) is a perennial tree species, oilseed, which has great importance in the semiarid region of Northeastern Brazil by preserving the river margins and the temporary stream. Due to the lack of information regarding the desiccation of oiticica seeds, the study aimed to evaluate the physiological quality of its seeds submitted to different drying periods. The experimental design was completely randomized and the data were submitted to analysis of variance and polynomial regression. The treatments were evaluated by determining the moisture content, seedling emergence, vigor tests (first count, emergency speed index, fresh and dry weight of shoots and roots), and grown analysis (number of leaves, seedling height and stem diameter). Oiticica seeds behave as orthodox, with increase on the emergency when its moisture content is reduced; the critical moisture content below which there is loss of viability is around $6 \%$.
\end{abstract}

Keywords: oiticica; emergency; desiccation; vigor.

1 Tecnóloga em Recursos Hídricos/Irrigação, Drª., Av. Teodorico Teles, 344, Bairro São Miguel, CEP 63122-430, Crato (CE), Brasil. eliduartebrandao@yahoo.com.br

2 Engenheiro Agrônomo, Dr., Professor do Departamento de Agricultura, Universidade Federal da Paraíba, Campus III, s/n, Cidade Universitária, CEP 58220-000, Bananeiras (PB), Brasil. alexandrediniz@ufpb.cchsa.br

3 Engenheira Agrônoma, Dra. ${ }^{\text {. }}$, Centro de Ciências Agrárias, Universidade Federal da Paraíba, Campus II, CEP 58397-000, Areia (PB), Brasil. lraraujo1@yahoo.com.br

4 Engenheiro Agrônomo, Dr., Professor Associado Aposentado do Departamento de Solos e Engenharia Rural, Centro de Ciências Agrárias, Universidade Federal da Paraíba, Campus II, CEP 58397-000, Areia (PB), Brasil. ivandrofranca@gmail.com

5 Engenheiro Agrônomo, Centro de Ciências Agrárias, Universidade Federal da Paraíba, Campus II, CEP 58397-000, Areia (PB), Brasil.wagner.magno1@gmail.com

6 Engenheira Agrônoma, Centro de Ciências Agrárias, Universidade Federal da Paraíba, Campus II, CEP 58397000, Areia (PB).gabismaioli@gmail.com 


\section{INTRODUÇ̃̃O}

O semiárido brasileiro apresenta grande diversidade de oleaginosas, cujo cultivo é restrito a fins alimentícios, no entanto, há um grande potencial a ser explorado, principalmente em relação ao aproveitamento energético de culturas temporárias e perenes (BELTRÃO; OLIVEIRA, 2007). Neste sentido, de acordo com Duque (2004) e Maia (2004), a funcionalidade do óleo extraído do fruto de Licania rigida Benth (oiticica) está na fabricação de tintas para impressoras de computadores e pintura de automóveis, indústria de vernizes, além de ser matéria-prima para saboaria e, ainda, segundo Beltrão e Oliveira (2007), pode também ser utilizado na fabricação de biodiesel, juntamente com outras oleaginosas.

Licania rigida Benth, pertencente à família Chrysobalanaceae, é uma planta típica do sertão nordestino com ocorrência nos estados do Piauí, Ceará, Rio Grande do Norte e Paraíba, em altitude de 50 até $300 \mathrm{~m}$, em solos aluvionais marginais de rios (DUQUE, 2004). Durante todo o ano, inclusive nos períodos de seca, comuns às regiões de ocorrência natural dessa planta, mantém-se verde e fornece sombra ao homem e diversos animais. Pode atingir até $20 \mathrm{~m}$ de altura e o seu tronco ramifica-se a pouca distância do solo e seu acentuado xerofilismo caracteriza-se pela perenidade de suas folhas grossas e ásperas, revestidas de cutícula espessa que protege a superfície contra a evaporação (BELTRÃO; OLIVEIRA, 2007).

A inflorescência é do tipo paniculado, com frutos do tipo drupa oblongo e com uma única semente rica em óleo (MAIA, 2004). A frutificação é tardia e irregular, emitindo brotação nova nos meses de maio e junho e as flores até o mês de outubro. A abertura das flores coincide com a época mais seca do ano (julho a dezembro), são, hermafroditas, amarelas internamente, de 2 a $3 \mathrm{~mm}$ de diâmetro aglomeradas em longos cachos. Após a fecundação das flores, os frutos começam a crescer rapidamente, os quais são ovais alongados, medindo de 4 a $6 \mathrm{~cm}$ de comprimento, com cerca de $2 \mathrm{~cm}$ de diâmetro, peso médio de 4 a $7 \mathrm{~g}$ e coloração castanha. De novembro até janeiro-fevereiro, em cachos pêndulos, os frutos se completam, amadurecem e caem (DUQUE, 2004).

São poucas as informações sobre a emergência e germinação da oiticica, no entanto, vários fatores podem interferir na qualidade das sementes durante o processo de produção como maturação, colheita, beneficiamento, manuseio, secagem e armazenamento. Neste caso, a redução do teor de água das sementes como resultado da secagem atua diretamente na diminuição do metabolismo, o que pode contribuir para diminuir a taxa de deterioração e aumentar o período em que podem ser armazenadas, sem perda da qualidade fisiológica (MARCOS FILHO, 2005). Segundo Dickie e Pritchard (2002), a tolerância à dessecação em sementes é a capacidade de recuperar as atividades metabólicas depois de quase completa a remoção da água presente no interior das mesmas, conservando sua germinabilidade e vigor. A capacidade fisiológica de tolerância à dessecação pós-colheita das sementes é variável entre as espécies, a maioria possui sementes que toleram dessecação a teores de água próximos de 2 a 5\%, sendo denominadas ortodoxas (FONSECA; FREIRE, 2003), as quais provavelmente dependem desse processo para redirecionar seu caminho metabólico em direção à germinação, diferentemente de outras sementes que não toleram dessecação para adquirir a capacidade germinativa e ainda, apresentam limites de tolerância à dessecação (BARBEDO; BILIA; FIGUEIREDO-RIBEIRO, 2002), geralmente a teores de água entre 15 e $20 \%$ sendo classificadas como recalcitrantes (HONG; ELLIS, 1996).

Devido à escassez de informações sobre a dessecação e a identificação do período de secagem ideal em sementes dessa espécie, objetivou-se com este trabalho avaliar a qualidade fisiológica de sementes de oiticica submetidas a diferentes períodos de secagem.

\section{MATERIAL E MÉTODOS}

O experimento foi conduzido em ambiente protegido pertencente ao Laboratório de Análise de Sementes (LAS), Departamento de Fitotecnia e Ciências Ambientais, do Centro de Ciências Agrárias, da Universidade Federal da Paraíba, Areia-PB.

Os frutos de Licania rigida Benth foram provenientes de 24 árvores-matrizes localizadas no município de Pombal-PB, região do sertão da Paraíba, com clima do tipo BSh semiárida quente, com evapotranspiração superior à precipitação de acordo com a classificação de Köppen (QUARESMA, 2014), os quais foram coletados do chão, acondicionados em sacos plásticos e conduzidos ao laboratório para o beneficia- 
mento mediante o processo de eliminação da casca de forma manual com o auxílio de um canivete, para a retirada das sementes. Após o beneficiamento, as sementes foram submetidas à secagem em estufa com circulação e renovação de ar, regulada a temperatura de $25-30^{\circ} \mathrm{C}$ constantes, pelos seguintes períodos: zero (sem secagem); $4 ; 8 ; 12 ; 16 ; 20$ e 24 horas, sendo que, a cada quatro horas foram retiradas amostras e submetidas às seguintes determinações: a) Teor de água - determinado em estufa regulada a $105 \pm 3^{\circ} \mathrm{C}$, durante 24 horas, conforme as Regras para Análise de Sementes (BRASIL, 2009), utilizando-se quatro repetições de cinco sementes. A porcentagem de umidade foi calculada em base úmida; b) Teste de emergência - quatro repetições de 25 sementes foram semeadas em bandejas plásticas com dimensões de 0,45 x 0,30 x 0,07 $\mathrm{m}$, contendo como substrato areia lavada e esterilizada em autoclave a uma profundidade de três centímetros e a umidade do substrato foi mantida por meio de regas diárias. As contagens foram feitas diariamente dos 16 aos 45 dias após a semeadura; c) Primeira contagem de emergência - realizada juntamente com o teste de emergência, a qual consistiu na porcentagem de plântulas emergidas aos 16 dias após a semeadura; d) Índice de velocidade de emergência (IVE) - determinado em conjunto com o teste de emergência dos 16 aos 45 dias após a semeadura, constando de contagens diárias no mesmo horário do número de plântulas emergidas, cujo índice foi calculado conforme a fórmula proposta por Maguire (1962):

$$
\mathrm{IVE}=\frac{\mathrm{G} 1}{\mathrm{~N} 1}+\frac{\mathrm{G} 2}{\mathrm{~N} 2}+\frac{\mathrm{G} 3}{\mathrm{~N} 3}+\cdots+\frac{\mathrm{Gn}}{\mathrm{Nn}}
$$

Em que: IVE = índice velocidade de emergência; G1, G2 e Gn = número de sementes germinadas a cada dia; N1, N2 e $\mathrm{Nn}=$ número de dias decorridos da semeadura da primeira, segunda até a última contagem.

Após a contagem final do teste de emergência (45 dias após semeadura), foram escolhidas ao acaso cinco plântulas normais (com três ou mais folhas e entre $15-20 \mathrm{~cm}$ de altura) de cada repetição e submetidas às seguintes medições: a) Número de folhas - contagem manual do número de folhas por plântula; b) Altura de plântulas - determinada com auxílio de uma régua graduada, medindo-se do colo da planta até o ponto de inserção da última folha e o resultado expresso em cm/plântula; c) Diâmetro caulinar - determinado com o auxílio de um paquímetro digital a cerca de um centímetro do solo com o resultado expresso em $\mathrm{mm} /$ plântula.

Em seguida foram separadas as raízes e parte aérea das plântulas, colocadas em sacos de papel para pesagem do material fresco e posteriormente, colocadas para secar em estufa regulada a $65^{\circ} \mathrm{C}$ por 48 horas. Decorrido esse período, o material foi pesado novamente. Utilizou-se balança de precisão de $0,001 \mathrm{~g}$, e os resultados foram expressos em $\mathrm{g} /$ plântula.

O delineamento experimental utilizado foi o inteiramente ao acaso, com quatro repetições de $25 \mathrm{se}-$ mentes por parcela. Os resultados foram inicialmente submetidos à análise de variância utilizando-se o teste $\mathrm{F}(\mathrm{p}<0,05)$ e de regressão polinomial, em que se testaram os modelos linear e quadrático, selecionando-se para explicar os dados significativos e com maior coeficiente de determinação $\left(\mathrm{R}^{2}\right)$.

\section{RESULTADOS E DISCUSSÃo}

O teor de umidade tem função representativa no comportamento das sementes quanto sua classificação em ortodoxas ou recalcitrantes (CARVALHO; NAKAGAWA, 2012), além de influenciar nas propriedades físicas e químicas de sementes de espécies arbóreas (CARVALHO; SILVA; DAVIDE, 2006). O aumento no tempo de secagem das sementes de Licania rígida Benth, diminuiu o teor de água de $8 \%$ no período zero (sem secagem) para aproximadamente 5,6\% no período de 24 horas de secagem, de forma lenta e gradual (Figura 1). Quaresma (2014) trabalhando com a mesma espécie observou comportamento semelhante. Segundo Santos-Moura et al. (2012), a redução do teor de água no início da dessecação pode ocorrer em função da maior quantidade de água nas camadas superficiais das sementes e, com o decorrer da evaporação, o processo torna-se mais lento, possivelmente devido à maior dificuldade de perda da água do interior das sementes. 


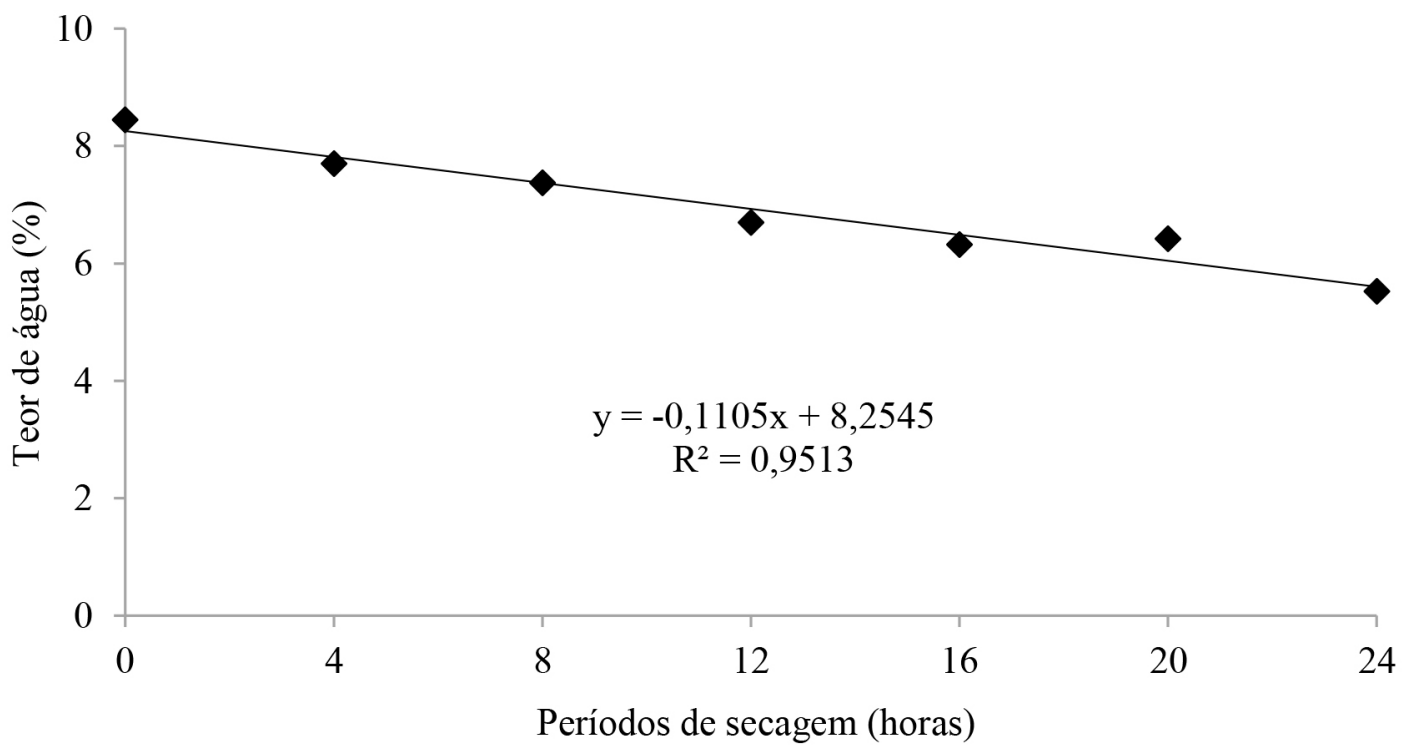

FIGURA 1: Teor de água de sementes de Licania rigida Benth após secagem das sementes por diferentes períodos. FIGURE 1: Moisture content of Licania rigida Benth after drying seeds for different periods.

Na porcentagem de emergência de plântulas (Figura 2) verificou-se que a secagem não interferiu no processo germinativo das sementes de oiticica, as quais podem ser classificadas como sendo ortodoxas. A tolerância à dessecação pode ser uma característica da família ou do gênero (HONG; LININGTON; ELLIS, 1996), e pode facilitar o armazenamento e ampliar o potencial de conservação, para fins de reposição das populações naturais (BARBEDO; BILIA; FIGUEIREDO-RIBEIRO, 2002). A redução do teor de água em sementes ortodoxas retarda consideravelmente os processos fisiológicos, como a respiração das sementes e o consumo de substâncias nutritivas armazenadas em seus tecidos de reserva, prevenindo a proliferação de fungos e bactérias (MEDEIROS; EIRA, 2006).

As sementes ortodoxas geralmente não só toleram a dessecação, mas provavelmente dependem dela para redirecionar seus processos metabólicos de desenvolvimento em direção à germinação. Em contraste, as recalcitrantes não apenas são independentes dessa secagem para adquirir a capacidade germinativa, como ainda têm limites de tolerância à dessecação. Essa diferença no comportamento das sementes pode ser considerada como resultado do processo de seleção natural, em concordância com as condições ambientais em que a espécie se desenvolveu (BARBEDO; MARCOS FILHO, 1998). Neste sentido, ressalta-se que a Licania rigida Benth é uma planta típica do sertão nordestino de clima semiárido, ou seja, passa por longos períodos de estiagem o que poderia ser uma forma de adaptação para sua propagação.

Outras espécies florestais foram classificadas como ortodoxas, como por exemplo, a Miconia argyrophylla DC e Metrodorea stipularis Mart (JOSÉ; SILVA; DAVIDE, 2007), Inga Ingoides (Rich.) Willd. (LAIME et al., 2011), pitombeira [Talisia esculenta (A. St. Hil) Radlk] (ALVES et al., 2008) e Caesalpiniae chinata Lam. (pau-brasil) (BARBEDO; BILIA; FIGUEIREDO-RIBEIRO, 2002). 


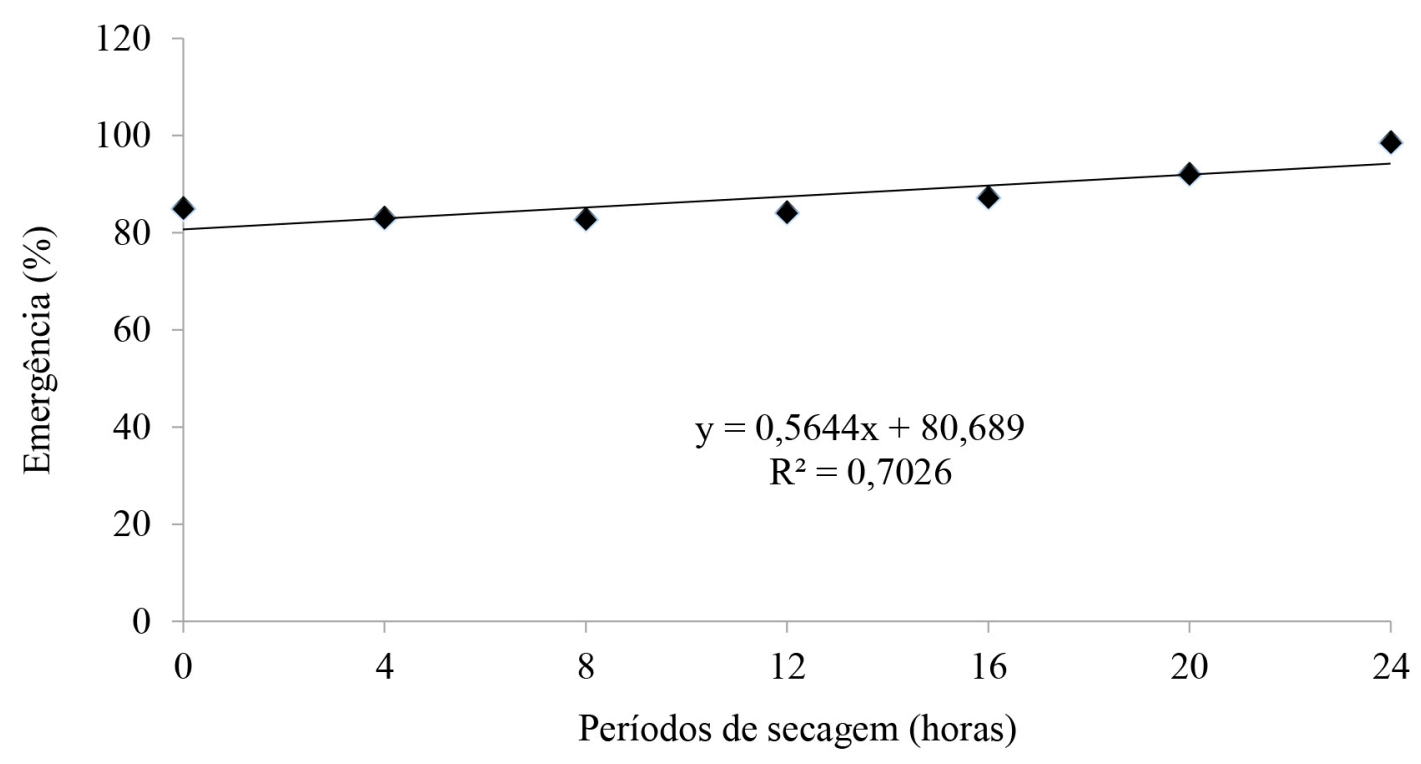

FIGURA 2: Emergência de plântulas de Licania rigida Benth após secagem das sementes por diferentes períodos. FIGURE 2: Seedling emergence of Licania rigida Benth after drying seeds for different periods.

Com relação ao vigor (dados da primeira contagem de emergência das plântulas), verificou-se que os dados ajustaram-se ao modelo de regressão polinomial quadrático com uma redução significativa dos valores em função dos períodos de secagem (Figura 3). O valor máximo $(20 \%)$ ocorreu no período de 8 horas de secagem, quando o teor de água encontrava-se em torno de 7,6\%. O vigor das sementes decresceu para aproximadamente $4 \%$ no período de 24 horas com um percentual de teor de água de 5,6\%, indicando que períodos superiores de 24 horas de secagem apresentam efeitos fisiológicos prejudiciais, podendo-se concluir que o teor de água crítico para a espécie está em torno de 6\%. Em sementes de Inga laurina (Sw.) Willd, Barrozo et al. (2014) constataram comportamento similar, com secagem em casa de vegetação, o vigor das plântulas decresceu na ocasião da primeira contagem desde o período sem secagem (zero), chegando a atingir valores de $2 \%$ após 29 horas de secagem. 


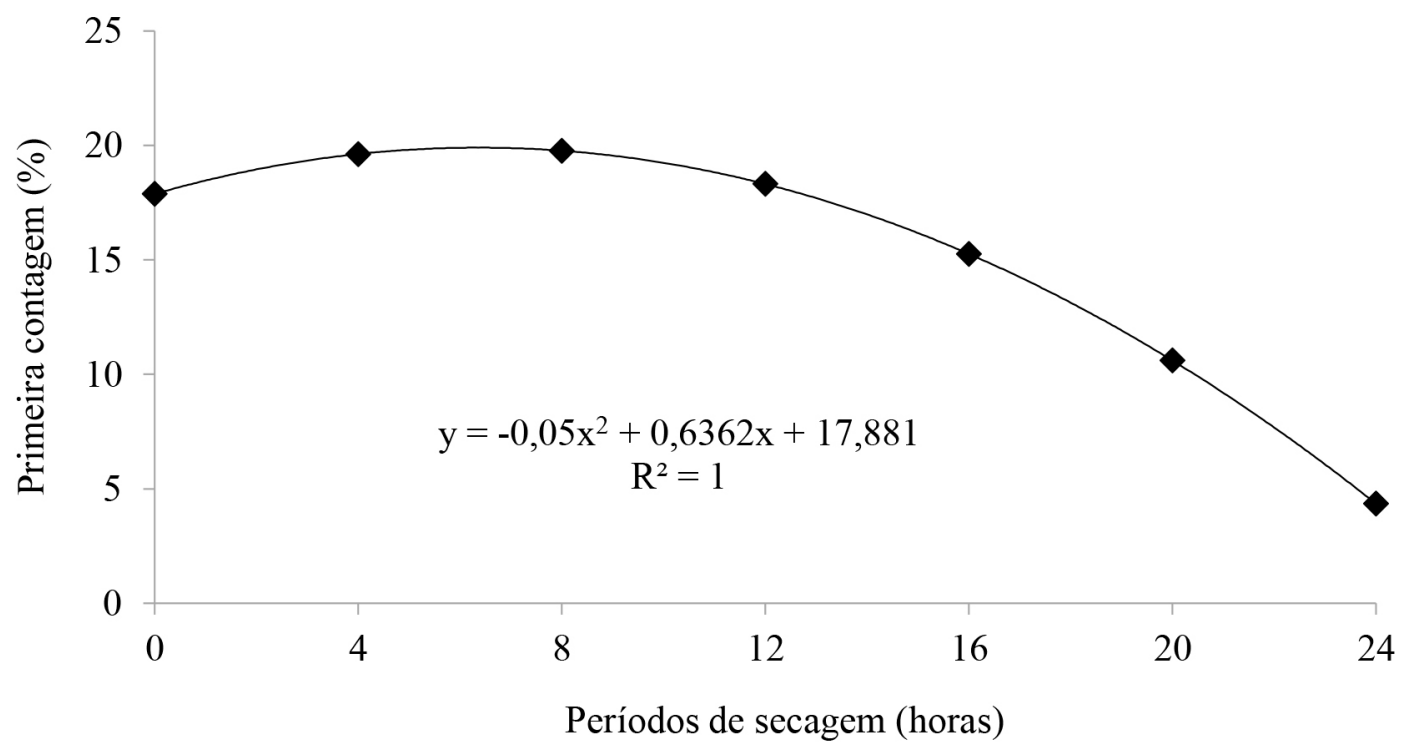

FIGURA 3: Primeira contagem de emergência de plântulas de Licania rigida Benth após secagem das sementes por diferentes períodos.

FIGURE 3: First count seedling emergence Licania rigida Benth after drying seeds for different periods

Quanto ao índice de velocidade de emergência constata-se que os valores decresceram linearmente (Figura 4), sendo que o maior valor alcançado $(0,95)$ foi obtido quando as sementes não foram secas (período zero), enquanto o menor $(0,60)$ no período de 24 horas de secagem. Porém, mesmo com os valores baixos, a secagem por diferentes períodos, como observado anteriormente (Figura 2), não afetou a emergência de plântulas normais. Santos-Moura et al. (2012) verificaram em sementes de cupiúva (Tapirira guianensis Aublet.) que os maiores índices de velocidade de germinação foram atingidos pelas que não foram submetidas à secagem (período zero), começando a reduzir drasticamente após este período até atingirem índices nulos em 12 horas de secagem. Os autores apontam que provavelmente a secagem provocou danos aos tecidos vitais das sementes, o que explicaria a redução drástica da germinação e do vigor após períodos mais prolongados de secagem.

Outros autores estudando espécies florestais observaram queda na qualidade das sementes após a secagem. Barrozo et al. (2014) observaram que o índice de velocidade de emergência de plântulas de Inga laurina (Sw.) Willd, oriundas de sementes secas em casa de vegetação, apresentaram decréscimo contínuo desde o primeiro período de secagem, atingindo vigor mínimo em 42 horas, com teor de água de 36,11\%. Alves et al. (2008) constataram que não houve influência dos períodos de secagem na porcentagem de emergência de plântulas de pitombeira [Talisia esculenta (A. St. Hil) Radlk]. No entanto, os autores evidenciaram que o vigor das mesmas foi prejudicado com a redução do teor de água de 40,23 para 39,41\%. Este fato também foi observado neste estudo, em que os períodos de secagem não prejudicaram na emergência de plântulas de oiticica (Figura 2), no entanto, para os testes de primeira contagem e índice de velocidade de emergência de plântulas (Figuras 3 e 4 ) houve reduções significativas com os períodos de secagem, principalmente a partir de 12 horas com teor de água de 6,9\%. De acordo com Prado (2012), a viabilidade das sementes é prejudicada pela redução do teor de água e, cada espécie possui um nível crítico e letal representado pelo grau de umidade no qual as sementes apresentam queda de vigor, ou tornam-se completamente inviável, respectivamente. Este mesmo autor, analisando sementes de Achras sapota L. verificou que o teor de água de $25 \%$ representa o ponto de máxima emergência de plântulas (99\%), no entanto, afirma que $16 \%$ é o teor de água crítico para essas sementes culminando com o aumento da porcentagem de plântulas anormais. 


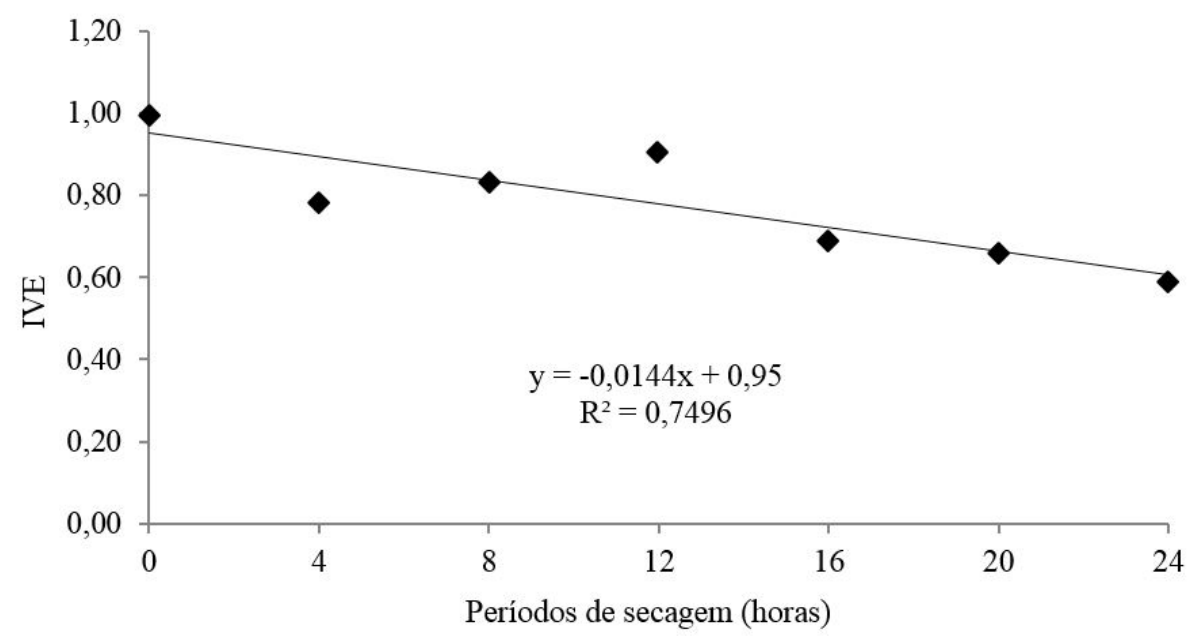

FIGURA 4: Índice de velocidade de emergência de plântulas de Licania rigida Benth após secagem das sementes por diferentes períodos.

FIGURE 4: Speed index of seedling emergence Licania rigida Benth after drying seeds for different periods.

Comparando-se os períodos de secagem das sementes de oiticica na análise de crescimento das plântulas, observou-se que não ocorreu efeito significativo para as variáveis, número de folhas, altura e diâmetro caulinar. No entanto, verificou-se efeito significativo para massa fresca e seca da parte aérea de plântulas e raízes, porém, os dados de massa fresca e seca da parte aérea não se ajustaram aos modelos linear e quadrático.

Para massa fresca e seca de raízes observou-se que houve efeito quadrático, alcançando valor máximo $(0,43 \mathrm{~g})$ de massa fresca em 12 horas, e valores mínimos $(0,20 \mathrm{~g})$ sem secagem (período zero) em 24 horas (Figura 5A). Já o valor máximo de massa seca de raiz $(0,26 \mathrm{~g})$ foi atingido com 8 horas, e apenas 0,07 g com 24 horas de secagem (Figura 5B). Esse teste de vigor demonstra que a qualidade fisiológica das sementes de oiticica foi prejudicada após as primeiras horas de secagem. Santos-Moura et al. (2012) também verificaram que a massa seca de plântulas de Tapirira guianensis Aublet reduziu significativamente com o aumento dos períodos de secagem, alcançando valor máximo $(0,024 \mathrm{~g})$ no período zero e reduzindo para $0,005 \mathrm{~g}$ após nove horas de secagem. 

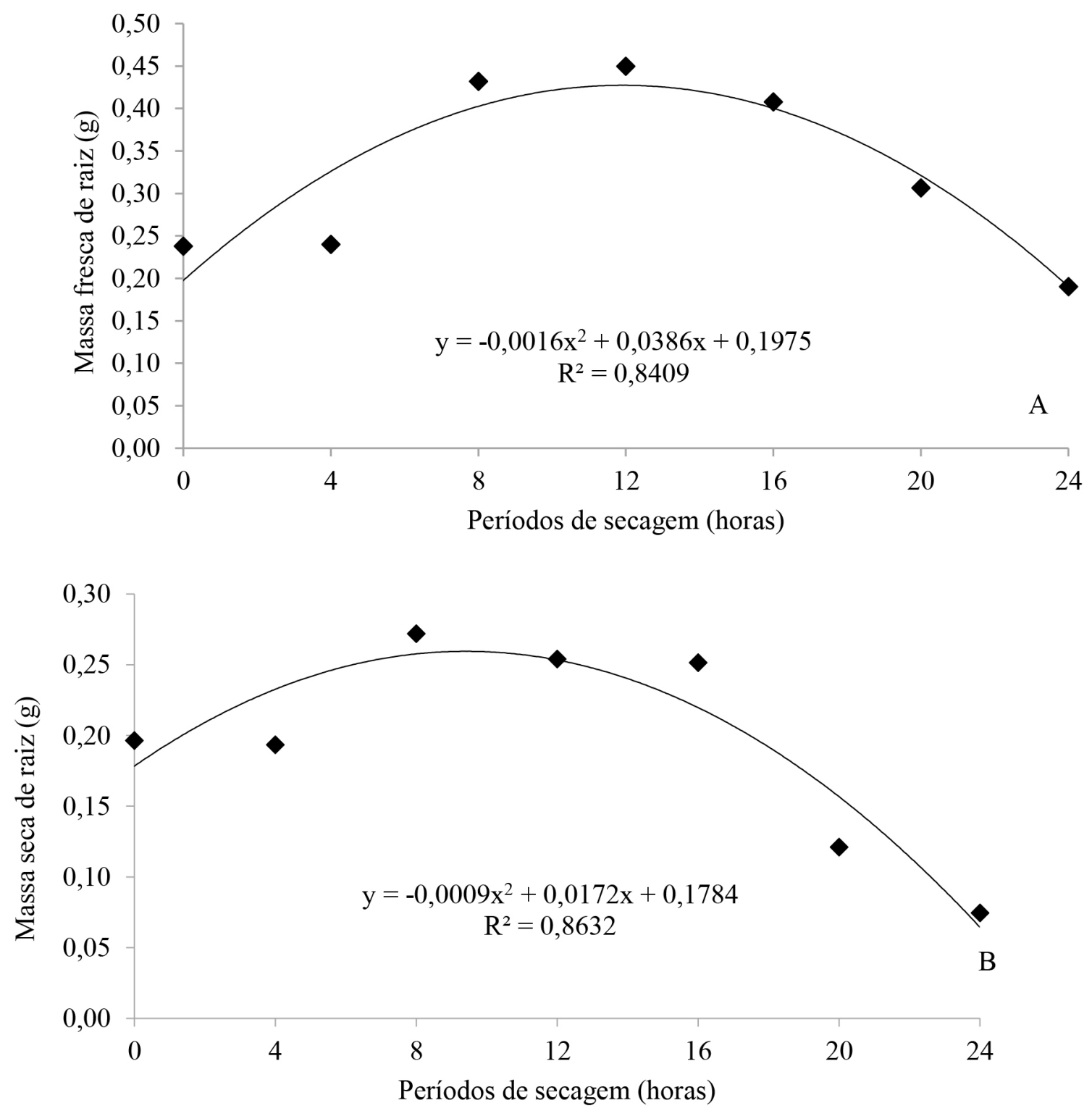

FIGURA 5: Massa fresca (A) e seca de raízes (B) de plântulas de Licania rigida Benth após secagem das sementes por diferentes períodos.

FIGURE 5: Fresh weight (A) and dry roots (B) of Licania rigida Benth after drying seeds for different periods.

\section{CONCLUSÃO}

As sementes de Licania rigida Benth comportam-se como ortodoxas, com elevada emergência à medida que seu teor de água é reduzido.

O nível crítico de água, abaixo do qual há perda de viabilidade, está em torno de $6 \%$.

\section{REFERÊNCIAS}

ALVES, E. U. et al. Comportamento fisiológico de sementes de pitombeira [Talisia esculenta (A. ST. Hil) Radlk] submetidas à desidratação. Revista Brasileira de Fruticultura, Jaboticabal, v. 30, n. 2, p. 509-516, jun. 2008.

BARBEDO, C. J.; BILIA, D. A. C.; FIGUEIREDO-RIBEIRO, R. C. L. Tolerância à dessecação e arma- 
zenamento de sementes de Caesalpiniae chinata Lam. (pau-brasil), espécie da Mata Atlântica. Revista Brasileira de Botânica, São Paulo, v. 25, n. 4, p. 431-439, dez. 2002.

BARBEDO, C. J.; MARCOS-FILHO, J. Tolerância à dessecação em sementes. Acta Botanica Brasilica, São Paulo, v. 12, n. 2, p. 145-164, 1998.

BARROZO, L. M. et al. Qualidade fisiológica de sementes de ingá em função da secagem. Bioscience Journal, Uberlândia, v. 30, n. 3, p. 645-654, maio/jun. 2014.

BELTRÃO, N. E. M.; OLIVEIRA, M. I. P. Oleaginosas potenciais do Nordeste para a produção de biodiesel. 1. ed. Campina Grande: Embrapa Algodão, 2007. 54 p. (Série Documentos, 177).

BRASIL. Ministério da Agricultura, Pecuária e Abastecimento. Regras para análise de sementes. Brasília: MAPA, 2009. 395 p.

CARVALHO, L. R.; SILVA, E. A. A.; DAVIDE, A. C. Classificação de sementes florestais quanto ao comportamento no armazenamento. Revista Brasileira de Sementes, Londrina, v. 28, n. 2, p. 15-25, 2006.

CARVALHO, N. M.; NAKAGAWA, J. Sementes: ciência, tecnologia e produção. 5. ed. Jaboticabal: FUNEP, 2012. $590 \mathrm{p}$.

DICKIE, J. B.; PRITCHARD, H. W. Systematic and evolutionary aspects of desiccation tolerance in seeds. In: BLACK, M.; PRITCHARD, H. W. Desiccation and survival in plants: drying without dying. Wallingford: CABI, 2002. p. 239-254.

DUQUE, G. O. Nordeste e as lavouras xerófilas. 4. ed. Fortaleza: Banco do Nordeste do Brasil, 2004. $330 \mathrm{p}$.

FONSECA, S. C. L.; FREIRE, H. B. Sementes recalcitrantes: problemas na pós-colheita. Bragantia, Campinas, v. 62, n. 2, p. 297-303, 2003.

HONG, T. D.; ELLIS, R. H. A protocol to determine seed storage behavior. Rome: International Plant Genetic Resources Institute, 1996. 62 p. (Technical Bulletin, 1).

HONG, T. D.; LININGTON, S.; ELLIS, R. H. Seed storage behaviour: a compendium. Rome: International Plant Genetic Resources Institute, 1996. 115 p. (Handbooks for Genebanks, 4).

JOSÉ, A. C.; SILVA, E. A.; DAVIDE, A. C. Classificação fisiológica de sementes de cinco espécies arbóreas de mata ciliar quanto à tolerância à dessecação e ao armazenamento. Revista Brasileira de Sementes, Londrina, v. 29, n. 2, p. 171-178, ago. 2007.

LAIME, E. M. O. et al. Emergência e crescimento inicial de plântulas de Inga ingoides (Rich.) Willd. em função da secagem das sementes. Engenharia Ambiental: Pesquisa e Tecnologia, Espirito Santo do Pinhal, v. 8, n. 3, p. 237-250, jul./set. 2011.

MAGUIRE, J. D. Speed of germination-aid in and evaluation for seedling emergence and vigour. Crop Science, Madson, v. 2, n. 2, p. 176-177, 1962.

MAIA, G. N. Caatinga: árvores e arbustos e suas utilidades. 1. ed. São Paulo: D \& Z, 2004. 413 p.

MARCOS FILHO, J. Fisiologia de sementes de plantas cultivadas. Piracicaba: FEALQ, 2005, 495 p.

MEDEIROS, A. C. S.; EIRA, M. T. S. Comportamento fisiológico, secagem e armazenamento de sementes florestais nativas. 1. ed. Colombo: Embrapa Floresta, 2006. 13 p. (Circular Técnica, 127).

PRADO, N. B. Dessecação e temperaturas na qualidade das sementes de Achras sapota L. 2012.57 f. Dissertação (Mestrado em Produção Vegetal) - Universidade Estadual de Santa Cruz, Ilhéus, 2012.

QUARESMA, J. M. Maturação e desenvolvimento de diásporos de Licania rígida Benth. 2014. $80 \mathrm{f}$. Monografia (Graduação) - Universidade Federal de Campina Grande, Patos, 2014.

SANTOS-MOURA, S. S. et al. Influência de diferentes períodos de secagem na qualidade fisiológica de sementes de Tapirira guianensis Aublet. Revista Brasileira de Fruticultura, Jaboticabal, v. 34, n. 2, p. 382-390, jun. 2012. 